\title{
A prospective randomised multicentre trial comparing 10 Fr Teflon Tannenbaum stents with 10 Fr polyethylene Cotton-Leung stents in patients with malignant common duct strictures
}

\author{
R E England, D F Martin, J Morris, M B Sheridan, R Frost, A Freeman, B Lawrie,
} $M$ Deakin, I Fraser, K Smith

Department of Radiology, South Manchester University Hospitals NHS Trust, Withington, Nell Lane, Manchester M20 2LR, UK

R E England

D F Martin

Department of Medical Statistics, South Manchester University Hospitals NHS Trust

J Morris

Department of Radiology, St James's Hospital, Leeds M B Sheridan

Department of Radiology, Salisbury Hospitals NHS Trust R Frost

Department of Radiology, Addenbrookes Hospital, Cambridge A Freeman

Department of Radiology, University Hospital Wales, Cardiff B Lawrie

Department of Surgery, North Staffordshire NHS Trust

M Deakin

Department of Surgery, Walsgrave Hospital, Coventry I Fraser

SMS Crowthorne, Berkshire, UK K Smith

Correspondence to: Dr England

Accepted for publication 22 September 1999

\begin{abstract}
Background-Stent blockage is a multifactorial process in which stent design and materials, bacteria, proteins, and bile viscosity play a role.

Aims-To compare the patency of the 10 Fr Teflon Tannenbaum (TT) stent to that of the 10 Fr Cotton-Leung (CL) polyethylene stent with sideholes, in patients with malignant obstructive jaundice.

Methods-Patients were recruited to this prospective multicentre randomised study if they had a newly diagnosed malignant bile duct stricture below the hilum of the liver suitable for stenting with a 10 Fr stent. Data were collected and monitored by a professional monitoring company. Primary patency was the interval between stent placement and first exchange or death without recurrent jaundice.

Results-134 consecutive patients were recruited between November 1994 and June 1997; 65 were randomised to the TT stent and 69 to the CL stent. Median patency and $95 \%$ confidence intervals were $181(59,303)$ days for the TT stent and $133(92,174)$ days for the CL stent, with no significant difference between the two stents $(p=0.49)$. Median survival and 95\% confidence intervals were 115 (71, 159) days for the TT stent and 151 (112, 190) days for the CL stent, with no significant difference between the two stents $(\mathrm{p}=\mathbf{0 . 7 6 5 )}$.
\end{abstract}

Conclusion-Neither Teflon as a stent material nor the Tannenbaum design prolong the patency of plastic stents. (Gut 2000;46:395-400)

Keywords: biliary prosthesis; patency; bile duct malignancy

Endoscopic biliary drainage is the preferred technique for palliation of inoperable malignant obstructive jaundice. Plastic stents are less expensive and remain a popular alternative to metallic stents. Their major drawback is their propensity to clog, often necessitating repeated stent changes in order to maintain biliary drainage.

The Teflon Tannenbaum (TT) stent (Cook UK, Letchworth, Hertfordshire; fig 1) is a straight stent with radial flaps at the proximal and distal ends but without sideholes. Seitz and colleagues ${ }^{1}$ compared 10 Fr TT stents with 10 Fr Teflon pigtail stents in patients with malignant distal biliary obstruction in a non-randomised study. They found a significant benefit in median patency of the TT stent over the Teflon pigtail stent (448 days versus 175 days, $p=0.02$ ). This finding is of note because a patency of 448 days compares favourably with the patency of expandable metal stents. The aim of our study was to compare the patency of the TT stent with the polyethylene straight Cotton-Leung (CL) stent (Cook UK, Letchworth, Hertfordshire; fig 1) in an attempt to confirm the prolonged patency of the TT stent.

\section{Patients and methods}

A prospective multicentre study was carried out at seven centres in the United Kingdom. Patients were recruited between November 1994 and June 1997 and were followed up until death or August 1998. Data were collected and monitored in accordance with the European Good Clinical Practice (GCP) guidelines ${ }^{2}$ by a professional monitoring company.

CRITERIA FOR ELIGIBILITY

Patients were included if they were above 18 years of age, and had a newly diagnosed malignant common duct stricture suitable for endoscopic stenting with a $10 \mathrm{Fr}$ prosthesis. Diagnosis of malignancy was based on clinical and imaging findings. A histological diagnosis was not necessary for inclusion. Patients with stents placed via a combined endoscopic and percutaneous procedure were included. $\mathrm{Pa}-$ tients were excluded if their lesion involved the bifurcation of the common hepatic duct, if they had a previous stent placed, previous bile duct surgery, or if they had advanced metastatic disease such that they were unlikely to survive to stent exchange.

TREATMENT

Patients who were potential study candidates gave informed consent prior to endoscopic retrograde cholangiopancreatography (ERCP). When deep cannulation was successful and cholangiography showed a suitable bile duct

Abbreviations used in this paper: $\mathrm{CL}$, Cotton-Leung; ERCP, endoscopic retrograde cholangiopancreatogram; GCP, Good Clinical Practice; NKP, needle-knife papillotomy; TT, Teflon Tannenbaum. 


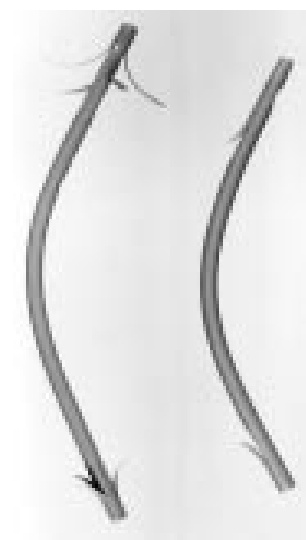

Figure 1 Left: the Teflon Tannenbaum stent; right: the polyethylene Cotton-Leung stent. stricture, patients were randomly assigned to either a $10 \mathrm{Fr}$ Cotton-Leung or $10 \mathrm{Fr}$ Tannenbaum prosthesis. Randomisation was performed by computer generated random numbers in sealed envelopes. Stenting was carried out using standard techniques. ${ }^{3}$

FOLLOW UP AND DEFINITION OF END POINTS

Patients were followed up by telephone one week after stenting and at two weekly intervals thereafter until death or the end of the follow up period in August 1998. Resolution of jaundice was determined clinically. If jaundice failed to resolve or if a patient developed signs or symptoms of stent dysfunction they had repeat ERCP with stent exchange. Stents were removed with retrieval forceps and slit open with a scalpel to confirm occlusion. If stents were not occluded (bile draining through the stent at exchange), note was made of any other factor which may be contributing to stent dysfunction. Stents were exchanged for similar type stents (TT for TT, CL for CL) and follow up continued to death or withdrawal. Complications of ERCP were assessed and recorded.

Patients were withdrawn from the study if they underwent surgery, or if after multiple frequent exchanges the investigator elected to place a different plastic stent or a metallic stent to improve drainage. The primary end point was the interval between stent insertion and first exchange or the presence of jaundice at

Table 1 Patient characteristics and clinical details for the overall group and for the two stent subgroups

\begin{tabular}{llll}
\hline Characteristics and clinical details & $\begin{array}{l}\text { Overall } \\
(n=134)\end{array}$ & $\begin{array}{l}\text { Tannenbaum } \\
(n=65)\end{array}$ & $\begin{array}{l}\text { Cotton-Leung } \\
(n=69)\end{array}$ \\
\hline $\begin{array}{l}\text { Sex } \\
\text { Male }\end{array}$ & $55(41 \%)$ & $31(48 \%)$ & $24(35 \%)$ \\
$\quad$ Female & $79(59 \%)$ & $34(52 \%)$ & $45(65 \%)$ \\
$\begin{array}{l}\text { Median (range) age (y) } \\
\text { ASA grade }\end{array}$ & $75.5(41-90)$ & $75(44-89)$ & $76(41-90)$ \\
I & $15(11 \%)$ & $6(9 \%)$ & $9(13 \%)$ \\
II & $93(69 \%)$ & $48(74 \%)$ & $45(65 \%)$ \\
III & $24(18 \%)$ & $10(15 \%)$ & $14(20 \%)$ \\
IV & $2(2 \%)$ & $1(2 \%)$ & $1(1 \%)$ \\
$\begin{array}{l}\text { Diagnosis } \\
\text { Pancreatic cancer }\end{array}$ & $94(70 \%)$ & $48(74 \%)$ & $46(67 \%)$ \\
$\quad$ Cholangiocarcinoma & $20(15 \%)$ & $12(18 \%)$ & $8(12 \%)$ \\
$\quad$ Metastatic nodes & $8(6 \%)$ & $1(2 \%)$ & $7(10 \%)$ \\
$\quad$ Ampullary cancer & $7(5 \%)$ & $2(3 \%)$ & $5(7 \%)$ \\
$\quad$ Miscellaneous & $5(4 \%)$ & $2(3 \%)$ & $3(4 \%)$ \\
Mean serum bilirubin (range) & $297.3(11-828)$ & $318.5(19-828)$ & $277.1(11-627)$ \\
$\quad(\mu m o l / 1)$ & $559(58.6-3682)$ & $471(93-3682)$ & $562(58.6-2655)$ \\
Median alkaline phosphatase & & & \\
$\quad$ (range) (IU/l) & & & \\
\hline
\end{tabular}

Table 2 Details of first stent procedure and response to stenting

\begin{tabular}{lllll}
\hline & $\begin{array}{l}\text { Overall } \\
(n=134)\end{array}$ & $\begin{array}{l}\text { Tannenbaum } \\
(n=65)\end{array}$ & $\begin{array}{l}\text { Cotton-Leung } \\
(n=69)\end{array}$ & $p$ Value \\
\hline Stricture site & & & & \\
$\quad$ Proximal CBD & $13(10 \%)$ & $7(11 \%)$ & $6(9 \%)$ & \\
$\quad$ Mid CBD & $38(28 \%)$ & $21(32 \%)$ & $17(25 \%)$ & \\
$\quad$ Distal CBD & $83(62 \%)$ & $37(57 \%)$ & $46(67 \%)$ & 0.51 \\
Technical success & $132(98.5 \%)$ & $63(97 \%)$ & $69(100 \%)$ & 0.46 \\
Sphincterotomy & $19(14 \%)$ & $7(11 \%)$ & $12(17 \%)$ & 0.33 \\
Needle-knife papillotomy & $47(35 \%)$ & $21(32 \%)$ & $26(38 \%)$ & 0.59 \\
Combined procedure & $6(5 \%)$ & $4(6 \%)$ & $2(3 \%)$ & 0.43 \\
Median stricture length (range) $(\mathrm{cm})$ & $2(1-8)$ & $2(1-7)$ & $2(1-8)$ & 0.65 \\
Median stent length (range) (cm) & $9(5-16)$ & $9(5-12)$ & $9(5-16)$ & 0.40 \\
Stent functioned (n=132) & $118(89 \%)$ & $53 / 63(84 \%)$ & $65 / 69(94 \%)$ & 0.11 \\
Complications & $9(7 \%)$ & $8(12 \%)$ & $1(1 \%)$ & \\
$\quad$ Perforation & $1(1 \%)$ & $1(1 \%)$ & 0 & \\
$\quad$ Pancreatitis & $3(2 \%)$ & $3(5 \%)$ & 0 & 0.01 \\
Cholangitis & $4(3 \%)$ & $3(5 \%)$ & $1(1 \%)$ & \\
Haemorrhage & $1(1 \%)$ & $1(1 \%)$ & 0 & \\
\hline
\end{tabular}

CBD, common bile duct. death without a stent exchange. If the patient died with a patent stent this time interval was recorded as censored data. Secondary end points were the number of stent exchanges and complications recorded in the two groups.

STATISTICAL ANALYSIS

To estimate the number of patients needed we used Seitz's patency rates of $55 \%$ at nine months for the TT stent and $35 \%$ at nine months for the pigtail stent with sideholes. For $80 \%$ power the required sample size was calculated to be 200 (100 in each group).

Patient survival and stent patency in the two groups were analysed using the Kaplan-Meier method and compared using the log rank test. The Mann-Whitney U test, the $\chi^{2}$ test, and Fisher's exact test were used for comparison of quantitative variables.

\section{Results}

PATIENT ENROLMENT AND CHARACTERISTICS

Between November 1994 and June 1997, 134 consecutive patients who met the inclusion criteria were recruited to the study. There were 55 men and 79 women, with a median age of 75.5 years (range 41-90 years). Sixty five patients were randomised to the TT stent and 69 to the CL stent. Patient characteristics and clinical details were similar in the two groups (table 1).

\section{STENTING PROCEDURE}

Histological confirmation of the diagnosis was obtained in only 18 of 134 patients (13\%). In the remainder diagnosis was confirmed by typical imaging findings and clinical course. Table 2 shows details of the first stenting procedure and response to stenting. The overall technical success rate was high $(98.5 \%)$ because patients were randomised after successful cholangiography. In two patients randomised to the TT prosthesis, stenting failed because of difficulty passing the stent through the papilla. It is not our routine practice to do sphincterotomy prior to stenting and therefore these patients were withdrawn. One of these had a non-study stent placed and one had surgery. Interestingly this was at the beginning of the study and was owing to the operator not being familiar with the TT stent which has a blunt tip and a row of radial flaps at its proximal end which increase the resistance to passage of the stent through the papilla. This problem was not encountered later in the study.

EARLY COMPLICATIONS AND 30 DAY MORTALITY Endoscopic sphincterotomy was performed in $19(14 \%)$ patients while needle-knife papillotomy (NKP) was used to gain access in 47 $(35 \%)$. Complications occurred in nine $(7 \%)$ patients overall: perforation in one, acute pancreatitis in three, cholangitis in four, and haemorrhage in one. There was a significant difference in the number of complications in the two stent groups, with eight of nine occurring in those stented with the TT stent.

Cholangitis occurred in both groups despite the use of prophylactic antibiotics prior to the procedure, and resulted in death in one patient. 
Table 3 Details of patients who failed to respond to first stent

\begin{tabular}{|c|c|c|c|c|c|c|}
\hline Stent & Diagnosis & Age (y) & $\operatorname{Sex}$ & $A S A$ & $\begin{array}{l}\text { Serum bilirubin } \\
(\mu m o l / l)\end{array}$ & Follow up and outcome \\
\hline$\overline{\mathrm{CL}}$ & Pancreatic cancer & 84 & $\mathrm{~F}$ & II & 404 & Died of disease at 23 days without exchange \\
\hline $\mathrm{CL}$ & Pancreatic cancer & 83 & $M$ & II & 350 & $\begin{array}{l}\text { Died of disease at nine days without exchange } \\
\text { Investigator thought that original stent too long. Replaced with }\end{array}$ \\
\hline CL & Pancreatic cancer & 43 & $\mathrm{~F}$ & I & 120 & shorter non-study $11.5 \mathrm{Fr}$ at seven days and had surgery \\
\hline CL & Cholangiocarcinoma & 86 & $\mathrm{~F}$ & III & 224 & $\begin{array}{l}\text { Died of disease at } 50 \text { days in hospice, no exchange } \\
\text { Palliative choledochoduodenostomy at } 14 \text { days. Died } 87 \text { days }\end{array}$ \\
\hline TT & Pancreatic cancer & 48 & M & I & 82 & $\begin{array}{l}\text { poststent } \\
\text { At seven days bilirubin 303; exchange. Stent not clogged but tip } \\
\text { abutting wall of duct. Successful stent (TT) exchange. Patent for }\end{array}$ \\
\hline TT & Cholangiocarcinoma & 78 & $\mathrm{~F}$ & III & 122 & $\begin{array}{l}145 \text { days. Still alive at } 607 \text { days } \\
\text { Tumour involving D } 2 \text {. Died at } 26 \text { days before palliative bypass }\end{array}$ \\
\hline TT & Pancreatic cancer & 70 & $M$ & II & 412 & $\begin{array}{l}\text { could be performed } \\
\text { Repeat ERCP at } 12 \text { days. Stent was occluded. Replaced }\end{array}$ \\
\hline TT & Pancreatic cancer & 81 & $\mathrm{~F}$ & II & 325 & $\begin{array}{l}\text { non-study stent which worked for } 97 \text { days till death of patient } \\
\text { No improvement. Died at } 13 \text { days, without exchange, of anuric } \\
\text { renal failure }\end{array}$ \\
\hline TT & Pancreatic cancer & 84 & $M$ & II & 620 & $\begin{array}{l}\text { Died of disease at } 15 \text { days, no exchange. } \\
\text { Had cholangitis poststenting but this responded to conservative } \\
\text { treatment. Bilirubin failed to decrease. Died of disease at } 27 \text { days, }\end{array}$ \\
\hline TT & Pancreatic cancer & 60 & $\mathrm{~F}$ & II & 260 & $\begin{array}{l}\text { without exchange } \\
\text { Had cholangitis poststenting and died of this at nine days, no }\end{array}$ \\
\hline TT & Cholangiocarcinoma & 75 & $\mathrm{~F}$ & II & 114 & $\begin{array}{l}\text { exchange } \\
\text { Had perforation at first procedure. Treated conservatively. At } 20 \\
\text { days exchanged stent for two non-study stents. Jaundice resolved }\end{array}$ \\
\hline TT & Pancreatic cancer & 72 & $\mathrm{~F}$ & II & 114 & $\begin{array}{l}\text { but patient died nine days later ( } 29 \text { days post first stent) } \\
\text { Exchanged at } 14 \text { days. Original stent too short. Replaced with }\end{array}$ \\
\hline TT & Pancreatic cancer & 86 & $\mathrm{~F}$ & II & 429 & longer stent, jaundice resolved, survived 155 days \\
\hline
\end{tabular}

Acute pancreatitis occurred in three patients stented with the TT stent. NKP was performed in two of these patients for access. All three responded to conservative therapy. In one patient retroperitoneal perforation occurred during stent placement though no sphincterotomy or NKP was performed. The perforation was treated conservatively but the stent did not function. A repeat procedure was performed at 20 days and two stents were placed for drainage. These stents resulted in resolution of jaundice; however, she died of her disease nine days later. The remaining patient had a haematemesis five days after stenting. No NKP or sphincterotomy was performed and bleeding was thought to be because of tumour invasion of the second part of the duodenum on diagnostic endoscopy.

The high rate of NKP in our study $(35 \%)$ may be attributable to a more aggressive endoscopic approach being taken in this group of patients with malignant disease, in whom failure to gain deep access to the bile duct would result in the need for percutaneous transhepatic stenting or surgery. Despite this rate of $\mathrm{NKP}$, complications of this procedure were not excessive.

The overall 30 day mortality was 22/134 $(16 \%): 14$ in the TT group $(\mathrm{p}=0.165)$ and eight in the CL group (NS). Of these only one died of a complication (see above). The remainder died of their disease. Eight had a non-functioning stent (see below) while $13 \mathrm{had}$ responded to drainage but died within 30 days of stenting; one patient in whom it was not possible to pass a stent died following surgery.

\section{RESPONSE TO STENTING}

The stent functioned in 118 of 132 (89\%) successfully stented patients. Jaundice failed to resolve in 10 stented with the TT stent and in four stented with the CL stent. Table 3 shows details of these patients and their subsequent management. Eight of fourteen died of their disease without stent exchange. One of these patients died of cholangitis as a complication of the stenting procedure. Six patients who failed to respond to initial stenting had further intervention. Two had surgery and five had stent exchange (one patient had both stent exchange and surgery). Of the five who had exchange the reason for stent dysfunction was inappropriate stent length in three, stent misplacement in one, and stent occlusion in one.

PATENCY OF FIRST STENT AND SURVIVAL

The Kaplan-Meier plot in fig 2 shows the patency of the first stent in the two subgroups. Of 132 patients, 56 (42\%) died or were withdrawn from the study with a patent stent, and are included as censored data. Seventy six (58\%) reached a definite end point of stent exchange or death with recurrent jaundice. The median (95\% confidence interval (CI)) patency in the TT group was $181(59,303)$ days and in the CL group $133(92,174)$ days. There was no significant difference in the patency of the two stents (log rank test; $\left.\chi^{2}(1)=0.5 ; \mathrm{p}=0.49\right)$. The Kaplan-Meier plot in fig 3 shows survival. Median (95\% CI) survival was $115(71,159)$ days in the TT group and $151(112,190)$ days in the CL group, with no significant difference between the two groups $(\mathrm{p}=0.765)$.

FOLLOW UP

At the end of the follow up period in August 1998 (530-1068 days follow up), six of 134 recruited patients were still alive. Five of these six had been withdrawn during the course of the study: two because a non-study stent had been placed inadvertently at exchange and were considered protocol violations; one with cholangiocarcinoma had a non-study stent placed after several exchanges to improve drainage; in one with cholangiocarcinoma the stent had migrated into the bile duct and could not be removed so a second stent was inserted alongside the first; and one patient was withdrawn when the first stent was removed to 


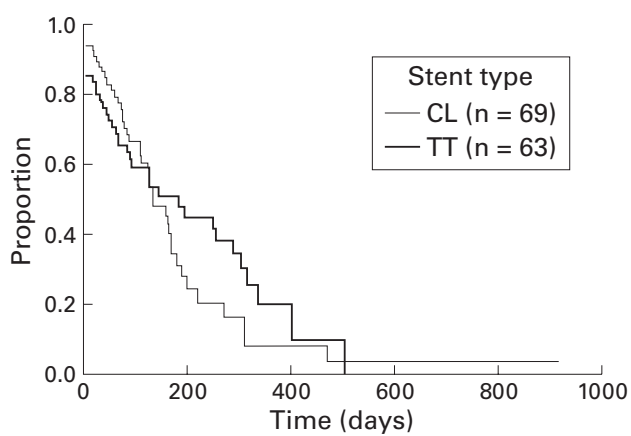

Figure 2 The Kaplan-Meier plots of patency of the first stent for the two groups. Note that estimates of patency are only accurate up to 297 days for the TT stent and 187 days for the CL stent.

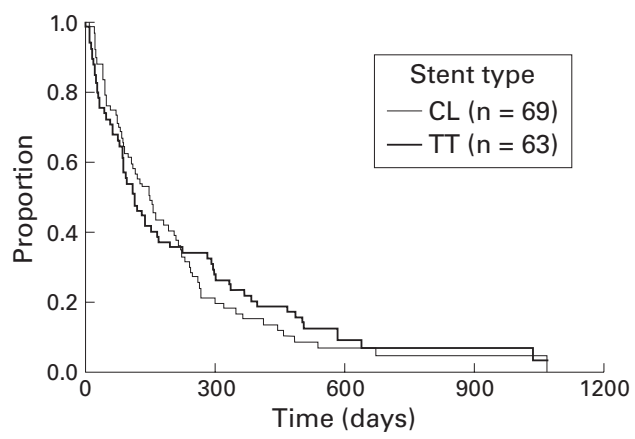

Figure 3 The Kaplan-Meier plots of survival for the two groups. Note that estimates of survival are only accurate up to 504 days for the TT stent and 390 days for the CL stent.

biopsy the stricture. This patient had negative histology and a subsequent diagnosis of chronic pancreatitis was made. The sixth patient alive at the end of the follow up period (at 914 days) had ampullary carcinoma and had remained free of jaundice without exchange of her CL stent.

Ninety two patients remained in the study until death and of these 56 were not jaundiced, 31 were jaundiced, four had resolving jaundice but died in the poststenting period, and in one information about jaundice was not available. Twenty two patients were withdrawn by the investigators during the course of the study because of failed passage of the initial stent, failed stent exchange, recurrent stent occlusions, and use of non-study stents; two patients had stent exchanges at non-study hospitals. Twelve patients were withdrawn because of subsequent attempted resection $(n=8)$ or palliative bypass surgery $(n=4)$. Two further patients were withdrawn because the patient or their carer refused follow up.

Surgery was performed in a total of 19 patients. Eight had Whipple's procedures, five had palliative double bypass, five had gastric bypass, and one had open and close laporotomy. A further patient developed gastric outlet obstruction during follow up and was managed with combined duodenal and biliary metal stenting.

STENT EXCHANGE

Stent exchange was attempted in 45 of 134 (34\%) patients (20 TT group, $25 \mathrm{CL}$ group) who either failed to respond to initial stenting or presented with recurrent jaundice. A suc- cessful study stent was replaced in 31, non-study stents were replaced in 10, and stent exchange failed in four patients. Twenty nine patients had one exchange procedure, eight had two exchanges, six had three exchanges, and one had four exchanges.

\section{Discussion}

Stent blockage is a multifactorial process in which stent characteristics, bacteria, proteins, and bile viscosity each play a significant role..$^{4-10}$ Attempts to reduce stent clogging have centred on the reduction of microbial colonisation and alterations in stent design. With regard to stent design and material, it has been shown in vitro that Teflon has the lowest coefficient of friction among all materials and thus the maximum potential for prevention of stent blockage. ${ }^{11}$

Initial stents had a pigtail configuration, for anchorage, and had multiple sideholes. However, the pigtail causes a considerable reduction in the flow capacity of the stent. ${ }^{67}$ The most popular plastic prosthesis in current use for malignant bile duct strictures is the straight polyethylene prostheses with a sidehole at each end such as the Cotton-Leung stent. The presence of sideholes may play a role in clogging. Coene and colleagues ${ }^{11}$ showed that not only do sideholes significantly increase the amount of sludge in stents but their presence eliminates any differences between materials, thus negating the theoretical advantage of using Teflon. Bruckner et $a l,{ }^{12}$ using $10 \mathrm{Fr}$ pigtail stents with large sideholes, found that $94 \%$ of their occluded stents were blocked at the sideholes. It is thought that altered bile flow rates and eddy currents at the sideholes enhance biofilm and bile encrustation. Sung et $a l_{,}^{13}$ however, found no difference in occlusion rates between polyethylene stents with and without sideholes.

This study was performed in an attempt to reproduce the results of Seitz and colleagues ${ }^{1}$ and to confirm prolonged patency of the TT stent. In a non-randomised study, ${ }^{1}$ the $10 \mathrm{Fr}$ TT stent $(n=55)$ and a $10 \mathrm{Fr}$ Teflon pigtail stent with sideholes $(n=74)$ were compared in 129 patients with malignant distal biliary obstruction. A remarkably prolonged median patency for the TT stent of 448 days (range 3-703) was reported, compared with a median patency of 175 days (range 6-636) for the Teflon pigtail stent $(\mathrm{p}<0.02)$. The median follow up was 141 days (range 3-703) in the TT group and 104 days (range 6-636) in the pigtail group. The median survival was 130 days (range 3-703) in the TT group and 100 days (range 6-636 days) in the Teflon pigtail group. A patency of 448 days for the TT stent compares favourably with the reported patency of self expanding metal stents, which are more expensive and permanent once placed, and this finding, if confirmed, would have important implications, particularly in terms of cost and the need for reintervention.

As the most common plastic stent in use is the straight polyethylene prosthesis with a single sidehole at each end, we chose to compare this stent with the TT stent. Our study population and inclusion criteria were similar to those of Seitz et al and we observed similar median 
survival times of 115 days for the TT stent and 151 days for the CL stent. Our 30 day mortality was $14 / 65(21.5 \%)$ in the TT group and $8 / 67$ $(11.9 \%)$ in the CL group; the groups of Seitz et al had a lower 30 day mortality of $4 / 55(7 \%)$ in the Tannenbaum group and 4/74 (5\%) in the pigtail group. All but one who died in our study within 30 days did so of their disease, and this difference in 30 day mortality may indicate that our patients were at a more advanced stage of disease than those of Seitz et al, although this information is not available from the paper. There were no early procedure related complications in the study of Seitz et al and the delayed stent related complications were stent migration of $4 / 52(8 \%)$ in the Tannenbaum group and $6 / 68(9 \%)$ in the pigtail group. Stent migration occurred in only two of 132 patients in our study and both migrations were in the TT group. The stent migrations of Seitz et al may be explained by their practice of performing a papillotomy in every patient to facilitate stent placement. We observed an early complication rate of $9 / 134(7 \%$; table 2$)$. It is of interest that there was a significantly higher rate of complications in the TT group $(8 / 65(12 \%)$ versus $1 / 69(1 \%)$ in the CL group, $p=0.01)$. The TT stent has a blunt tip and a row of radial flaps at its proximal end which increase resistance to the passage of the stent and may result in more trauma to the pancreatic duct orifice, leading to the higher rate of post-ERCP pancreatitis. Cholangitis occurred in both our groups despite the use of prophylactic antibiotics in all patients. A higher incidence of cholangitis was seen in the TT group, but numbers are too small to draw conclusions.

Our median patency was 181 (CI 59, 303) days for the TT stent compared with 133 (CI $92,174)$ days for the CL stent. Although there were many patients who died with a patent stent our median values are based on a reasonable number of patients (24/65 in the TT group and 36/67 in the CL group were alive at the median patency); however, the fairly wide 95\% confidence intervals reflect the fact that the estimates are not based on a very large sample. Seitz and colleagues ${ }^{1}$ quote median patency of 448 days (range 3-703) in the Tannenbaum group. However, from the published data the median patency value must be based on a small number of patients and thus is unlikely to be an accurate estimate; the 95\% confidence intervals unfortunately are not quoted. The Kaplan-Meier curve of their stent patency data (fig 4), shows that the patency of the Tannenbaum group is 0.55 between 215 days and 448 days; this is not dissimilar to our median patency of the TT stent of 181 days.

A criticism of our study may be that we were unable to recruit 200 patients; the reduced sample size of 134 has led to a reduction in power. Nevertheless our overall numbers compare favourably with those in the study of Seitz et al. Our study was prospective, randomised, and monitored by an independent monitoring company, and we are confident that our data are accurate.

VanBerkel and colleagues ${ }^{14}$ recently published a prospective randomised study compar-

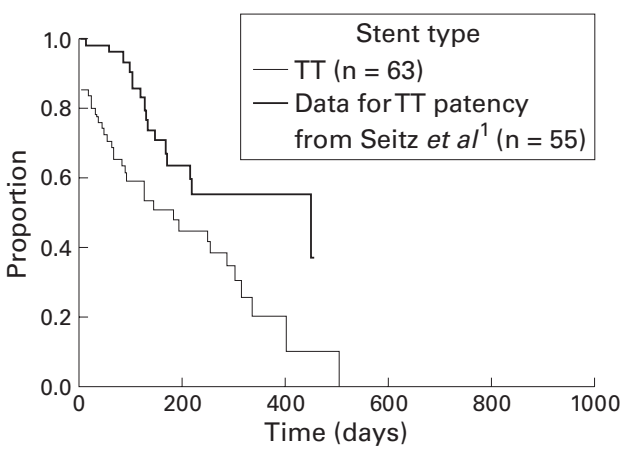

Figure 4 The Kaplan-Meier plots of our data for TT patency compared with those of Seitz et al.

ing the patency of a straight $10 \mathrm{Fr}$ "Amsterdam" style Teflon stent (with a single side hole and flap at each end) to a similar size and design of polyethylene stent in patients with distal bile duct malignancy. The median patency of the Teflon stent was 83 days (range 4-223) and that of the polyethylene stent was 80 days (range 3-257). The authors acknowledge the relatively poor patency of their stents overall and suggest this may be because of the large number of their patients who had a previous failed cannulation at ERCP with contamination of bile by contrast and bacteria. They were unable to show any beneficial effect of Teflon on patency. Their Teflon stent was examined under the scanning electron microscope and multiple surface irregularities were noted; they suggest that these may act as a surface to which biofilm and sludge can adhere, nullifying the benefit of Teflon's low frictional coefficient.

In conclusion, neither Teflon as a stent material nor the lack of sideholes seem to prolong significantly the patency of plastic stents. We have found no improvement in patency or clinical outcome with the TT stent over the standard commonly used polyethylene CL stent. As stent clogging is a multifactorial process this fact is not surprising.

The authors would like to thank Cook UK (Letchworth, Hertfordshire) who sponsored this study and funded Dr England's post as Cook Fellow from 1994 to 1996.

1 Seitz U, Vadeyar H, Soehendra N. Prolonged patency with a new-design Teflon biliary prosthesis. Endoscopy 1994;26:478-82.

2 European GCP guidelines. 1st ed. Surrey: Brookwood Medical Publications Ltd, 1993.

3 Martin DF, Tweedle DEF, Haboubi NY. Techniques and complications. In: Martin DF, Tweedle DEF, Haboubi NY, eds. Clinical practice of ERCP. London: Churchill Livingeds. Clinical practice of

4 Speer AG, Cotton PB, MacRae KD. Endoscopic management of malignant biliary obstruction: stents of 10 French gauge are preferable to stents of 8 French gauge. Gastrointest Endosc 1988;34:412-17.

5 Leung JWC, DelFavero G, Cotton PB. Endoscopic biliary prostheses: a comparison of materials. Gastrointest Endosc 1985;31:93-5.

6 Rey JF, Maupetit P, Greff M. Experimental study of biliary endoprosthesis efficiency. Endoscopy 1985;17:145-8.

7 Siegel JH, Pullano W, Kodsi B, et al. Optimal palliation of malignant bile duct obstruction: experience with endoscopic12Fr prostheses. Endoscopy 1988;20:137-41.

8 Leung JWC, Ling TKW, Kung JLS, et al. The role of bacteria in the blockage of biliary stents. Gastrointest Endosc 1988;34:19-22.

9 Speer AG, Cotton PB, Rode J, et al. Biliary stent blockage with bacterial biofilm: a light and electron microscopy with bacterial biofilm: a light and Intern Med 1988;108:546-53.

10 Coene LO. Human bile viscosity in endoscopic biliary drainage. In: Endoscopic biliary stenting: mechanisms and possible solutions of the clogging phenomenon. Maastricht: Datawyse, 1990:135-51. 
11 Coene LO, Groene AK, Cheng J, et al. Clogging of biliary endoprostheses: a new perspective. Gut 1990;31:91317.

12 Bruckner M, Seitz U, Mack D, et al. Vergleichende Untersuchungen uber Rinnen- und Silberprosthesen bei der drainage maligner Gallengangsstenosen. Fortschr Gastroenterol Endosk 1990;20:17-21.
13 Sung JJY, Chung SC, Tsui CP, et al. Omitting side-holes in biliary stents does not improve drainage of the obstructed biliary system: a prospective randomised trial. Gastrointest Endosc 1994;40:321-5.

14 Van Berkel AM, Boland C, Redekop WK, et al. A prospective randomised trial of Teflon versus polyethylene stents for distal malignant biliary obstruction. Endoscopy 1998;30:681-6. 